\title{
Research on the Relationship between the Competitiveness of High-Tech Enterprises and Enterprise Value
}

\author{
Fengzhou Wang \\ School of Business Administration \\ Jimei University \\ Xiamen, China \\ fzhwang@jmu.edu.cn
}

\author{
Yanyue Zhang \\ School of Finance and Economics \\ Jimei University \\ Xiamen, China \\ zhangyanyue9@163.com
}

\begin{abstract}
Since the $1980 \mathrm{~s}$, enterprise management has entered the stage of value management with the goal of maximizing enterprise value. In order to achieve the goal of maximizing value, companies must compete. Therefore, how to continuously enhance the competitiveness of enterprises to maximize the value of enterprises is a major issue that enterprise managers must seriously consider. Based on whether it shows competitive advantage, this paper divides enterprise competitiveness into revealed competitiveness and dynamic capabilities. By constructing multiple linear regression models, we study the impact of revealed competitiveness and dynamic capabilities on enterprise value. The empirical results show that both revealed competitiveness and dynamic capabilities can positively affect enterprise value, but environmental dynamism will weaken the impact of both on enterprise value.
\end{abstract}

Keywords-Enterprise competitiveness; enterprise value; dynamic capabilities; environmental dynamism

\section{INTRODUCTION}

In order to achieve the goal of value-added, enterprises must compete with each other in the factor market and product market. In the dynamically changing environment, the firm continued to raise their competitiveness is an important means to realize this goal. According to the "China Torch Statistical Yearbook", since the issuance of the "Management Measures for the Qualification Recognition of High-tech Enterprises" in 2008, the number of high-tech enterprises recognized by the state has risen sharply. By the end of 2017, there are 130,632 high-tech enterprises in China. Taking high-tech enterprises as an example to study the relationship between enterprise competitiveness and enterprise value, on the one hand because high-tech enterprises are more sensitive to the dynamically changing environment than other enterprises; on the other hand, high-tech enterprises continue to enhance enterprises competitiveness through learning, imitation and independent innovation.

\section{LITERATURE REVIEW}

As the source of competitive advantage, relevant theories of enterprise competitiveness include: the five-force competition model, resource-based theory, capability-based theory, and knowledge theory. Scholars explore the relationship between enterprise competitiveness and enterprise value from the perspectives of market structure, resources, capabilities and knowledge. In general, the relationship between the two is as follows:

\section{A. Enterprise competitiveness is positive correlation with enterprise value}

After development, the connotation of firm competitiveness includes the resources, capabilities and knowledge that cause the heterogeneity of enterprises. Most scholars agree that corporate competitiveness is positively related to corporate value. The empirical research of this kind of viewpoint generally divides the competitiveness according to industry or ability characteristics, and studies the impact of each subdivision ability on enterprise value. For example, [1] divided enterprise competitiveness into the ability to respond to the market and the ability to respond to the government, and discuss the impact of these two capabilities on business performance. Reference [2] divided the enterprise capabilities into static and dynamic capabilities, and discussed the mechanism and impact of these two capabilities on corporate performance. Reference [3] based on project management ability, technical ability, human resource management ability, relationship management ability, knowledge ability and service provision ability, designed the evaluation index of outsourcing enterprise competitiveness, and discussed the impact of each component ability on enterprise performance.

Although such research considers the direct effects of each component on enterprise value, it does not consider whether there is a correlation between the various components, nor whether the influence of individual components on the firm value will be affected by other components. The impact of environmental dynamism is not taken into account.

\section{B. Enterprise competitiveness is regarded as enterprise value}

Enterprise competitiveness is regarded as the comprehensive strength of the enterprise, and part of the research regards enterprise competitiveness as a synonym for enterprise value. This understanding is reflected in the evaluation indicators of enterprise competitiveness and enterprise value is similar. Both [4] and [5] equate competitive advantage with excess returns and directly use financial 
performance indicators to measure competitive advantage. This phenomenon is also common in China. When selecting the evaluation index of enterprise competitiveness, [6] adopted cash flow, [7] chose return on equity. Both indicators measure business value.

For this kind of viewpoint, this paper believes that the purpose of shareholders to create a business is to obtain more benefits through the enterprise and create greater value, that is, the maximization of enterprise value is the root cause of the existence of the enterprise. The purpose of enterprises to enhance their competitiveness is to achieve value-added. Therefore, this paper believes that enterprise competitiveness is not equivalent to enterprise value.

\section{The relationship depends on the situation}

Reference [8] analyzed the logical and philosophical basis of competitive advantage based on Bayes' theorem. It argued that the two hidden hypotheses in the study of competitive advantage lead scholars to misunderstand the relationship between corporate competitiveness and corporate value. Competitiveness does not necessarily lead to profits. Reference [9] believed that the relationship between corporate competitiveness and corporate value depends on the competitive conditions of the industry. Reference [10] took Apple as an example to argue that competitiveness has a strong correlation with corporate earnings; and PetroChina as an example to demonstrate that there is a weak correlation between sustainable competitiveness and corporate earnings; ultimately, the relationship will depend on many other factors.

In summary, based on whether competitiveness has demonstrated competitive advantage, this paper subdivides enterprise competitiveness into revealed competitiveness and dynamic capabilities, and considers the impact of the dynamic environment and market competition intensity to study the relationship between enterprise competitiveness and enterprises value.

\section{RESEARCH HYPOTHESIS}

This paper divides the competitiveness of enterprises into revealed competitiveness and dynamic capabilities based on whether they have demonstrated competitive advantage. The revealed competitiveness refers to the competitiveness generated based on the resources, capabilities and knowledge accumulated by the enterprise in the past. It has already demonstrated competitive advantage in the market and helped companies achieve good performance. In [11], dynamic capabilities are the ability to reconstruct capabilities based on changes in the environment. It can reconstruct resources, capabilities, and knowledge by resource integration, learning, and innovation to enhance corporate competitiveness.

\section{A. Research hypothesis of revealed competitiveness and enterprise value}

In the buyer's market, customer value is the main source of corporate value. The higher the revealed competitiveness means that the company's products have a competitive advantage in terms of quality, performance, service and customer relationship compared with other companies in the same industry, and can provide a higher customer value. Higher customer value means: 1) The company's products have a high reputation and acceptance in the hearts of customers, and have a high market share. 2) the substitutability of products is low, which can ensure stable cash flow and reduce business risks. 3) The heterogeneity of the product/service is large, and the bargaining power of the customer is reduced. The enterprise can sell products at a higher price. 4) The market share of products is larger, which has a great influence on the material market. When purchasing raw materials, raw materials can be obtained at a lower price.

Therefore, this paper proposes the following assumptions:

H1: revealed competitiveness is positively related to enterprise value.

\section{B. The regulating effect of environmental dynamism on the relationship between revealed competitiveness and enterprise value}

According to the theory of business, to add value of the enterprise must ensure that the environment is compatible with revealed competitiveness, otherwise the theory of business of the enterprise will be invalid. It means that companies do not have the ability to achieve corporate missions in their environment. Therefore, higher environmental dynamism will weaken the role of revealed competitiveness in enterprise value. Therefore, this paper proposes the following assumptions.

H2: The stronger the environmental dynamism, the weaker the effect of revealed competitiveness on enterprise value.

\section{Dynamic capabilities and enterprise value}

Enterprises with strong dynamic capabilities can quickly respond to external environmental and market changes, avoiding enterprises from getting into trouble and reducing business risk losses. Therefore, this paper makes assumptions value.

H3: Dynamic capabilities are positively related to enterprise

\section{Dynamic capabilities and revealed competitiveness}

While helping companies adapt to the external environment, dynamic capabilities also discover new resource combinations, foster new technologies and new knowledge by resource integration, learning and innovation, and provide more sources for revealed competitiveness.

Therefore, this paper proposes the following assumptions:

H4: Dynamic capabilities are positively correlated with revealed competitiveness.

H5: revealed competitiveness plays a mediating role in the relationship between dynamic capabilities and corporate value.

\section{E. The regulation of environmental dynamism}

When the external environment of the enterprise changes rapidly, the accuracy of the organization to understand the environment will be reduced. Firstly, Enterprise is less sensitive to the external environment, and the ability to avoid 
risks will be reduced. Secondly, resources and capabilities of enterprise restructuring are not valuable in the changed market, which will cause the company to bear a large loss. Thirdly, when the external environment dynamism is high, the effective time of revealed competitiveness is shortened, and the influence of revealed competitiveness on corporate value is also weakened. Therefore, based on the above analysis, the following hypotheses are proposed:

H6a: The stronger the environmental dynamism, the smaller the effect of dynamic capabilities on enterprise value.

H6b: The stronger the environmental dynamism, the smaller the effect of dynamic capabilities on revealed competitiveness.

H6c: The stronger the environmental dynamism, the smaller the effect of revealed competitiveness on firm value.

\section{RESEARCH DESIGN}

\section{A. Sample and Data}

This paper takes the data of Chinese listed companies that have been awarded the qualifications of high-tech enterprises for 2015-2017 as a sample (including subordinate companies identified as high-tech enterprises). When selecting data, the following criteria are followed: (1) Excluding financial and insurance companies; (2) Excluding ST and ST* companies; (3) Excluding samples with less than 5 years of listing; (4) Excluding samples with missing data. After screening, a total of 1053 data were obtained. This paper uses stata.14 for empirical analysis.

\section{B. Variable selection and definition}

a) Enterprise value. This paper uses the Tobinq to measure the enterprise value. b) Revealed competitiveness (rec). This paper measures the revealed competitiveness based on the results of competition, and chooses six indicators including net assets, increase rate of business revenue, net profit growth rate, return on equity, return on total assets and overall labor productivity. This paper uses the entropy method to obtain the weight of each indicator. c) Dynamic capabilities (dc). This paper uses the total asset turn over to reflect the ability of enterprise resource integration, and the proportion of students with undergraduate and above reflects the learning absorption capacity of enterprises; the proportion of intangible assets reflects the ability of enterprise innovation; and uses the entropy method to measure the weight of each indicator. d) Environment dynamism(ed). This paper uses the coefficient of variation of abnormal income of enterprises to measure the dynamic environment of enterprises. e) Control variables. This paper chooses the nature of the enterprise, the concentration of ownership, the concentration of the industry, and the year of establishment of the company as control variables.

\section{Model}

In order to test the role of revealed competitiveness on corporate value, this paper sets up Model 1 and Model 2.

$$
\text { tobinq }=a_{0}+a_{1} * r e c+a_{2} * \text { nature }+a_{3} * \text { top } 1+a_{4} * c r 4+a_{5} * a g e+\varepsilon_{1}
$$

$$
\begin{aligned}
\text { tobinq } & =b_{0}+b_{1}{ }^{*} \text { rec }+b_{2} * e d+b_{3}{ }^{*} \text { rec } * e d \\
& +b_{4}{ }^{*} \text { nature }+b_{5}{ }^{*} \text { top } 1+b_{6}{ }^{*} c r 4+b_{7} * a g e+\varepsilon_{2}
\end{aligned}
$$

According to the hypotheses H3, H4, H5, H6a, H6b, H6c, the relationship between dynamic capabilities and firm value is applicable to the moderated mediator model. Therefore, this paper set up Model 3, Model 4, and Model 5.

$$
\begin{aligned}
& \text { tobinq }=c_{0}+c_{1} * d c+c_{2} * e d+c_{3} * d c * e d+c_{4} * \text { nature } \\
& +c_{5} * \text { top } 1+c_{6} * \text { cr } 4+c_{7} * \text { age }+\varepsilon_{3} \\
& \text { rec }=d_{0}+d_{1} * d c+d_{2} * e d+d_{3} * d c * e d \\
& +d_{4} * \text { nature }+d_{5} * \text { top } 1+d_{6} * c r 4+d_{7} * \text { age }+\varepsilon_{4} \\
& \text { tobinq }=e_{0}+e_{1} * d c+e_{2} * e d+e_{3} * d c * d+e_{4}^{*} \text { rec } \\
& +e_{5}{ }^{*} \text { rec } * e d+e_{6}{ }^{*} \text { nature }+e_{7} * \text { top } 1+e_{8}{ }^{*} \mathrm{cr} 4 \\
& +e_{9} * a g e+\varepsilon_{5}
\end{aligned}
$$

\section{StatistiCAl ANALYSIS}

\section{A. Descriptive statistics and correlation analysis}

The minimum value of Tobinq is 0.929 , and the maximum value is 10.60 , which indicates that there is a difference in enterprise value. The median dynamic capacities (dc) is 0.115 , which is much lower than $1 / 2$ of the maximum dynamic capabilities (0.544), indicating that the dynamic capabilities of most high-tech companies are generally low. The minimum value of revealed competitiveness (rec) is 0.0424, the maximum value is 0.637 , and the standard deviation is 0.0648 , indicating that the distribution of revealed competitiveness is relatively uniform. The minimum value of environmental dynamism (ed) is 0.00750 , and the maximum value is 1.186 , indicating that there is a big difference in the dynamic environment of the enterprise. The statistical results are shown in Table I:

TABLE I. DESCRIPTIVE ST ATISTICS

\begin{tabular}{|c|l|l|l|l|}
\hline & \multicolumn{1}{|c|}{ min } & \multicolumn{1}{c|}{ Max } & \multicolumn{1}{c|}{ P50 } & \multicolumn{1}{c|}{ Sd } \\
\hline Tobinq & 0.929 & 10.60 & 2.596 & 1.761 \\
\hline Rec & 0.0424 & 0.637 & 0.321 & 0.0648 \\
\hline Dc & 0.0278 & 0.544 & 0.115 & 0.0733 \\
\hline Ed & 0.00750 & 1.186 & 0.163 & 0.159 \\
\hline
\end{tabular}

In order to explain the relationship between enterprise competitiveness and enterprise value, this paper conducts a Pearson test on the main variables. The results show that there is a correlation between the variables in the model, but the correlation coefficients are much less than 0.5 , indicating that there is no multicollinearity between the variables. The test results are shown in Table II:

TABLE II. PEARSON CORRELATION COEFFICIENT

\begin{tabular}{|c|l|l|l|l|}
\hline & \multicolumn{1}{|c|}{ Tobinq } & \multicolumn{1}{c|}{ Rec } & \multicolumn{1}{c|}{ Dc } & Ed \\
\hline Tobinq & 1 & & & \\
\hline Rec & $0.240^{* * *}$ & 1 & & \\
\hline Dc & $0.197^{* * *}$ & $0.115^{* * *}$ & 1 & \\
\hline Ed & $0.051^{*}$ & $-0.198^{* * *}$ & $0.211^{* * *}$ & 1 \\
\hline
\end{tabular}




\section{B. Multiple regression analysis}

In the following, the regression of five models is carried out by stata14.0. The effects of revealed competitiveness and Dynamic capabilities on enterprise value are analyzed. The results of the regression analysis are shown in Table III.

TABLE III. RESULTS OF REGRESSION ANALYSIS

\begin{tabular}{|c|c|c|c|c|c|}
\hline Variable & Model 1 & Model 2 & Model 3 & Model 4 & Model 5 \\
\hline Rec & $\begin{array}{l}0.203^{* * *} \\
(0.0287) \\
\end{array}$ & $\begin{array}{l}0.253^{* * *} \\
(0.0298) \\
\end{array}$ & & & $\begin{array}{l}0.211^{* * *} \\
(0.0300)\end{array}$ \\
\hline ed & & $\begin{array}{l}0.0571 \\
(0.0297)\end{array}$ & $\begin{array}{l}-0.00947 \\
(0.0290)\end{array}$ & $\begin{array}{l}- \\
0.270 * * * \\
(0.0299)\end{array}$ & $\begin{array}{l}0.0180 \\
(0.0300)\end{array}$ \\
\hline rec_ed & & $\begin{array}{l}-0.139 * * * \\
(0.0299)\end{array}$ & & & $\begin{array}{l}-0.111^{* * *} \\
(0.0296)\end{array}$ \\
\hline Dc & & & $\begin{array}{l}0.240 * * * \\
(0.0294)\end{array}$ & $\begin{array}{l}0.174 * * * \\
(0.0303)\end{array}$ & $\begin{array}{l}0.193 * * * \\
(0.0294)\end{array}$ \\
\hline dc_ed & & & $\begin{array}{l}-0.0718^{*} \\
(0.0285)\end{array}$ & $\begin{array}{l}- \\
0.122 * * * \\
(0.0294)\end{array}$ & $\begin{array}{l}-0.0412 \\
(0.0281)\end{array}$ \\
\hline R2 & 0.157 & 0.181 & 0.173 & 0.120 & 0.214 \\
\hline $\mathbf{F}$ & 38.88 & 33.01 & 31.20 & 20.30 & 31.52 \\
\hline $\mathbf{N}$ & 1053 & 1053 & 1053 & 1053 & 1053 \\
\hline
\end{tabular}

1) The relationship between revealed competitiveness and enterprise value.

As can be seen from TableIII, the results of Model 1 show that revealed competitiveness is significantly positively correlated with firm value $\left(\mathrm{a}_{1}=0.203, \mathrm{p}<0.001\right)$. In Model $2, \mathrm{~b}_{3}$ is $-0.139, p<0.001$, indicating that the environmental dynamism negatively regulates the relationship between revealed competitiveness and enterprise value. This paper assumes that $\mathrm{H} 1, \mathrm{H} 2$ are established.

\section{2) Dynamic capabilities and enterprise value}

The model of the relationship between dynamic capabilities and firm value is a mediating model with adjustment. Based on the regression results, this paper first analyzes the mediating effects and analyzes the mediating effects of regulation.

In Model $3, \mathrm{c}_{1}$ is $0.240, \mathrm{p}<0.001$ indicates that dynamic capability is significantly positively correlated with corporate value. The assume that $\mathrm{H} 3$ is established. In Model $4, \mathrm{~d}_{1}$ is $0.174, \mathrm{p}<0.001$, indicating that dynamic capability is significantly positively correlated with revealed competitiveness. The assume that $\mathrm{H} 4$ is established. In Model 5 , $\mathrm{e}_{4}$ is $0.211, \mathrm{p}<0.001$. In summary, revealed competitiveness plays a mediating role in the relationship between dynamic capabilities and corporate value, $\mathrm{H} 5$ is established.

In model $3, c_{3}$ is $-0.0718, p<0.05$, indicating that environmental dynamism has a negative effect on the direct effect of dynamic capability and firm value, H6a is established. In model $4, \mathrm{~d}_{3}$ is $-0.122, \mathrm{p}<0.001$, indicating that environmental dynamism has a negative regulation effect on the first half of the mediating effect, H6b is established. In model $5, \mathrm{e}_{5}$ is $0.111, \mathrm{p}<0.001$, indicating that environmental dynamism has a negative regulation effect on the second half of the mediating effect, H6c is established.

\section{CONCLUSIONS}

According to the correlation analysis and regression analysis, the paper draws the following conclusions: 1) Both revealed competitiveness and dynamic capabilities can significantly positively affect firm value. 2) Revealed competitiveness plays a mediating role in the relationship between dynamic capabilities and corporate value. 3) Whether it is the relationship between revealed competitiveness and corporate value, or the relationship between dynamic capability and corporate value, environmental dynamism plays a negative adjustment role.

\section{REFERENCES}

[1] Xu Lei,Tang Xiaohua, "Double Ability" and Business Performance of Enterprise Competitiveness, $10^{\text {th }}$ ed, vol.27.soft science, 2013, pp.87 91.( In Chinese)

[2] Wang Shumin, How does enterprise capability "moving” and "quiet" combination to improve corporate performance?-Tracking research from the perspective of competence theory, $9^{\text {th }}$ ed, vol.30. Management review, 2018, pp.121-131.(In Chinese)

[3] Zhu fulin, Institutional environment, outsourcing ability and performance improvement, $2^{\text {nd }}$ ed, vol.41.Jinan Journal (Philosophy and Social Sciences Edition), 2019, pp:1-14.(In Chinese)

[4] Foss N J, Knudsen T, The Resource-Based Tangle: Towards a Sustainable Explanation of Competitive Advantage, $4^{\text {th }}$ ed, vol.24. Managerial \& Decision Economics, 2003, pp.291-307.

[5] Robert R. Wiggins, Timothy W. Ruefli, Schumpeter's Ghost: Is Hypercompetition Making the Best of Times Shorter? $10^{\text {th }}$ ed, vol.26.Strategic Management Journal, 2005, pp.887-911.

[6] Li Yanlin, Cheng Jun, Li Qiang, R\&D investment, achievement transformation and enterprise competitiveness, $9^{\text {th }}$ ed, Friends of Accounting, 2014, pp.54-58. (In Chinese)

[7] Li Wenqian, Liu Yi, Technology Innovation, Corporate Social Responsibility and Enterprise Competitiveness-An Empirical Analysis Based on Data of Listed Companies, $1^{\text {st }}$ ed, vol.38.Science and Science and Technology Management, 2017, pp.154-165. (In Chinese)

[8] Powell T C, Competitive Advantage: Logical and Philosophical Considerations, $9^{\text {th }}$ ed, vol.22.Strategic Management Journal, 2001, pp. 875-888.

[9] Jin Bei, Li Gang, Profitability and competitiveness of Chinese enterprises, $11^{\text {th }}$ ed, China's industrial economy, 2007, pp.5-14. (In Chinese)

[10] Deng Bing, Research on sustainable competitiveness from the perspective of enterprise value and dynamic earnings information, Hunan University,2015. (In Chinese)

[11] David J. Teece, Gary Pisano and Amy Shuen, Dynamic capabilities and strategic management, Strategic Management Journal, 1997, Vol.18 (7), pp.509-533. 